\title{
“My thoughts shifted from the past to the future": Time and (autobio)graphic representation in Miné Okubo's Citizen 13660
}

\author{
James Peacock
}

Keele University

*Email: j.h.peacock@keele.ac.uk

\begin{abstract}
This article explores time in Miné Okubo’s graphic memoir Citizen 13660. Drawing on the work of Homi Bhabha, and on comics scholars like Thierry Groensteen, it argues that Okubo's complex representation of time serves several functions. First, it undermines expectations of the linear memoir form by making links between different panels, thus forcing the reader to reconsider historical continuities and breaks. Secondly, it shows how authority figures responsible for the internment of Japanese Americans during World War II consciously manipulated ideas of time, history and lineage in order to cast Japanese Americans as dangerous others. Thirdly, ironic contrasts between words and images in Citizen 13660 serve to undermine racialized ideological constructions and begin to deconstruct hegemonic ideas about national identity and belonging.
\end{abstract}

Keywords: Miné Okubo;Citizen 13660 ;time;Japanese Americans World War Two;graphic autobiography

There is no room in this country for hyphenated Americanism. [ ... ] There is no such thing as a hyphenated American who is a good American. (Theodore Roosevelt, quoted in "Roosevelt Bars the Hyphenated” 1915)

This is an article about time. More specifically, it is about the delicacy with which Miné Okubo, author of the graphic memoir Citizen 13660 ([1946] 2014), depicts the two-and-a-half years she spent in the Japanese internment camps during World War II. Not only does Okubo's memoir provide an invaluable record of this episode, combining a personal narrative with a chronicle of an ethnic group whose sense of identity was transformed by external 
political forces, but it also reveals, with great subtlety, how time is intimately bound up in perceptions of individual, communal and national identity, and in power relations. The interplay of verbal and visual elements in Citizen 13660 is integral, because it encourages the reader "to perceive time spatially” (McCloud 1993, 100) by means of recurring visual motifs and ironic relationships between words and images. Moreover, these relationships allow Okubo to position herself "in complex fashion as both an insider and an outsider within the borders of her own community" (Creef 2004, 80) and thus to question the construction of identities.

Drawing on comics scholarship, primarily the work of Thierry Groensteen (2007), as well as postcolonial theorists of national and ethnic identity, this article enters into colloquy with existing criticism on Citizen 13660 by focussing primarily on temporal issues. Scholars such as Vivian Fumiko Chin (2004), Elena Tajima Creef (2004), Heather Fryer (2008) and Xiaojing Zhou (2007) have shown how Okubo offers nuanced visual and textual representations of Japanese Americans in order to counteract the racist stereotypes promulgated by the government and the media as part of their propaganda drive during the war. As Creef argues, visual representations help to shape how ethnic groups are perceived, and, in the case of Japanese Americans, show that "racial difference is both defined and contained within the framework of enemy aliens, model minorities, and an idealized notion of white American citizenship” (2004, 6-7). Zhou in particular also analyses the strategies of 
"spatial exclusion, deprivation, and confinement" $(2007,68)$ which, in combination with racist stereotypes, served to de-individualise Japanese Americans and mark them as disloyal and dangerous. According to Zhou: “Okubo’s use of pictorial autobiographical narration and her deft combination of words and images provocatively reveal the process by which Japanese Americans' identity as the 'enemy race' was spatially constructed along with the spatial production of fear by state power” (52). I aim to supplement Zhou's very persuasive reading, expanding the analysis to explore, following Mikhail Bakhtin's well-known formulation, the full chronotopic potential of Citizen 13660. For as well as showing how public and private space was manipulated and redefined in order to prejudice the wider American public against Japanese Americans, Okubo's graphic memoir demonstrates how time was also used as a means of oppression by government and camp authorities. Moreover, in persecuting an ethnic population "on the basis of their ancestry" (52), the authorities attempted to redefine Japanese Americans' prior histories, and in so doing identify them as aliens with a dangerously diminished sense of "loyalty" to the nation.

In pursuing these lines of inquiry, my article explores a number of interconnected areas. First, the generic aspects of Citizen 13660 - that is, its status as an autobiography which sometimes confirms, sometimes destabilizes readerly expectations about temporal causality. Secondly, Okubo's descriptions of how time was controlled by the camp authorities. Thirdly, the formal aspects of Okubo's work, including her skilful transitions between text, images 
and pages and her sparing but always significant use of comics conventions such as motion lines for ironic effect. Finally, the role that conceptualizations of time play in the construction of citizenship and of ethnic and national identity. If Citizen 13660 functions in part as a reassertion of Japanese American identity through the creation of a unique representational space (one in which each picture is marked, as Phillips [2005] observes, with a signature that can easily be read as the possessive pronoun "mine" [23]), then it also begs to be interpreted as a reassertion of time, through the retelling of a subaltern group's story that re-inscribes Japanese Americans' history for readers. Okubo’s manipulations of temporality encourage empathy with the characters, and remind us how time is constructed in the service of power and control. They also require readers' active engagement, and in this respect Citizen 13660 is typical of comics narratives, even if it differs in other ways from what we now identify as comics (there is only ever one image on any page, for example, and text and image are kept separate).

A postcolonial perspective is valuable partly because the hybridity of the graphic memoir is ideally suited to depicting the complexity of such matters as nationality and hyphenated identities. As Sidonie Smith (2011) argues:

The sequential art of graphic memoir presents readers with boxes of memory, filled with images and words, arrayed across the gaps that are gutters, and linked through the 
self-referential 'voiceover' that presents in turn narration, description, emotive reaction, meditation, or metacommentary on the process of remembering. Their hybridity encodes and routes meaning in multiple directions. (67)

So a postcolonial approach to the graphic memoir will surely illuminate how the experience of Japanese Americans during World War Two demonstrates the instability and arbitrariness, of concepts such as national identity, ethnicity and belonging. According to Viet Thanh Nguyen and Tina Chen (2000), scholarly studies of Asian America have been dominated by Chinese and Japanese Americans because these groups have been in the United States the longest:

The experiences of Chinese and Japanese Americans, proceeding from exclusion, discrimination and persecution to relative inclusion and assimilation, are oriented around the primary importance of the nation and national identity. Thus, the need to 'claim America' has been integral to the self-representation of Chinese and Japanese American identity. (para. 3)

In challenging both the centrality of Chinese and Japanese Americans and the importance of American national identity to discussions of Asian American identity, Nguyen and Chen aim 
to focus more attention on other Asian American groups, including "Filipinos, Koreans, Pacific Islanders, South Asians, and Southeast Asians, whose nations and cultures have been colonized by Europeans, Americans, and other Asians” (para. 3). Additionally, they seek to highlight "the fact that homelands and diasporas become new and potentially contradictory foci for Asian American cultures”; the global diaspora of populations represents neither "a step towards a utopian dissolution of borders” nor a complete dismissal of the concept of nation (para. 4) but it does complicate the notion of belonging for many Asian Americans.

While Nguyen and Chen's postcolonial approach and their desire to look beyond Chinese and Japanese Americans are compelling, their contention that these groups have generally striven to "claim America” is problematic. Indeed, following the logic of their own arguments, “America” becomes an inherently unstable entity, a place of hyphenated and hybrid populations with a supplementary relationship to other homelands and imagined communities. Moreover, they suggest that "the reconception of the United States as part of the Americas in general, making it a postcolonial space built on the successful colonization of Mexico, Hawaii, and the Philippines” (Nguyen and Chen 2000, para. 7), would better equip postcolonial critics to study these hybrid populations. Therefore, even if a book such as Citizen 13660 partly constitutes an attempt to “claim” America, such a claim needs to be challenged for its totalising sweep.

This is not least because the rhetoric and actions of the US authorities and mainstream 
media around the time of Franklin D. Roosevelt's executive order of 19 February 1942 deliberately provoked questions of competing nations, homelands and affiliations, thus, ironically, problematizing the notion of American national identity more widely. As Stella Oh (2008) argues, Okubo's graphic memoir "performs a theory of citizenship, one that is conceived through the irony and contestation found in the internment” (146). One of the deepest ironies, of course, is performed in the title, which appears to confer citizenship even as it robs Okubo of a name and identity.

In a seven-page series of images near the beginning of the book, Okubo shows vividly how the outbreak of war with Japan led to rhetorical and representational strategies that sought radically to reposition and redefine Japanese Americans. During this sequence of panels, a generic shift is enacted: what begins as a conventional autobiography, dominated by the first-person "I", becomes a wartime memoir of a persecuted group, filtered through the observing I/eye but chiefly characterised by the plural pronouns “we,” “us” and “our”. The sudden slippage, for Okubo, her relatives and her friends, from domestic comfort and familiarity to strangeness, threat and displacement is illustrated both pictorially and in the shocking tonal alteration in language employed to describe Japanese Americans collectively. As we will see, the careful, precise appellations Okubo's text uses to refer to Japanese Americans in this sequence emphasize the temporal aspects of their ethnic identity. Temporality, linked to lineage and homeland, is readily exploited in debates about national 
loyalties.

After Okubo returns to California from Switzerland, we see her enjoying a meal with friends (Figure 1). She is positioned at the head of the table, and many dinner party guests are looking in her direction, as if confirming her centrality to the autobiography, before she becomes observer and reporter. The accompanying text is laconic: "I had a good home and many friends. Everything was going along fine” (Okubo [1946] 2014, 7). Written years later by the narrating Okubo, it marks the first of the book's important ironic temporal contrasts between words and images. For the Okubo who writes - armed, like the reader, with fuller knowledge of what transpired - is by no means identical to the Okubo at the table who can know nothing of the ramifications of the attack on Pearl Harbor on December 7, 1941. On the one hand, this is an example of a conventional trick of autobiography - the retrospective creation of narrative beats to excite tension or, in this case, dramatic irony. But in a graphic narrative, with visual and verbal elements in constant negotiation and with words that, as Scott McCloud's analysis strongly implies, are best considered alongside images (indeed, as images) on a spectrum of abstraction from reality $(1993,49)$, the autobiographical impulse becomes even more layered and complex and its claims to objective "truth" even more qualified. 
caption: (Okubo [1946] 2014, 7)]

For example, in the panel depicting Okubo’s dinner party there are correspondences to another image of collective dining later in the story — the Tanforan camp mess hall (Figure 2). In this picture, Okubo is no longer at the head of the table, but is instead squeezed into the corner of the panel alongside other internees. The look she exchanges with the woman to her left is far removed from the placid expressions shared by the dinner party guests; it is suspicious and confrontational, implying the threat to group solidarity engendered by camp conditions. As the text reveals: “Table manners were forgotten. Guzzle, guzzle, guzzle; hurry, hurry, hurry. Family life was lacking. Everyone ate wherever he or she pleased. Mothers had lost all control over their children” (Okubo [1946] 2014, 89).

[INSERT FIGURE 2 HERE

caption: Okubo [1946] 2014, 89]

According to Thierry Groensteen (2007), tracing such correspondences is a matter of "braiding," of seeking the "additional and remarkable structuration” lying beyond linear relations and beyond the straightforward implied movement of panels in sequence (146). The discovery of congruities in, for example, these dining panels, affects the readers' 
understanding of "before" and "after" partly by encouraging an active form of reading both forwards and backwards, and partly by subtly calling into question the incommensurability of the attack on Pearl Harbor and the subsequent persecution of Japanese Americans. In other words, the prejudicial treatment of a particular ethnic group may not result just from an unexpected epochal event (though of course one like Pearl Harbor might accelerate discrimination), but may also derive from historical continuities, and from already deeply rooted ideologies of national identity, belonging and otherness. ${ }^{1}$ In this postcolonial context, it is clear that race is a key factor. The attack on Pearl Harbor played a large part in the subsequent persecution of Japanese Americans, but it is also true that there was no widespread persecution of German Americans or Italian Americans during World War Two. Theodore Roosevelt's loathing of hyphenation (seen in the epigraph) derives in large part from complex identities supposedly made visible by markers of racial difference, an aspect that Okubo emphasises through her graphic storytelling.

Next, Okubo and her brother are shown at breakfast, listening to the radio when the attack on Pearl Harbor is announced: Okubo's language here marks her first direct engagement with her ethnicity: "We were shocked. We wondered what this would mean to us and the other people of Japanese descent in the United States" ([1946] 2014, 8). Not only does the use of the first-person plural denote the memoir's need to represent collective experience and group solidarity, but it also highlights lineage through the use of the word 
“descent”. This word - which also connotes Japanese Americans' imminent fall on hard times - must be read chronotopically, because it carries both the sense of movement through space and a temporal aspect related to ancestry. It can suggest a dichotomy between "before" (Japan) and "after" (America), between "the past" and "the present". However it is interpreted, it imbues national identity with a vital historical sense.

Growing suspicion toward Japanese Americans is shown in the next panel by means of a characteristic visual motif in Citizen 13660 - the gaze. As Okubo, standing on a busy street, reads the headline announcing the US's declaration of war against Japan, a pedestrian looks back at her with an expression of sombre contemplation, marking her racial difference ([1946] 2014, 9). The positioning of Okubo's signature on the man's coat signals the reclamation of his look in the act of writing Citizen 13660, and Okubo's turning of her gaze back upon suspicious citizens and active persecutors in the act of representing her experiences. Nonetheless, on the next page, Okubo's difference is foregrounded as the US's entry into the war exacerbates anti-Japanese rhetoric. Although newspapers feature throughout the text's opening pages, this panel eschews the initial realistic aesthetic in order to focus specifically on media rhetoric. Surrounded by what Zhou dubs "scare headlines" $(2007,59)$ and with a newspaper open before her on the desk, Okubo looks directly at the reader, with a mixture of distress and defiance. ${ }^{2}$ The racist epithets of the headlines contrast with the careful language of Okubo's commentary (Figure 3). While she refers to "Japanese 
American friends” and “American citizens and aliens of Japanese ancestry” ([1946] 2014, 10-11) - betraying a desire to maintain a distinction between Nisei and Issei (second and first-generation Japanese Americans) which is rudely shattered when everyone, "regardless of citizenship” is ordered to evacuate ([1946] 2014, 17) - the headlines refer to "citizens of Jap ancestry” and exclaim: “DON’T TRUST A JAP” ([1946] 2014, 10). The positioning of these media slogans around the figure of Okubo, according to the genre's conventions of captions and speech bubbles, suggests they also emanate from her, implying that such pervasive, hegemonic prejudice can infiltrate the victim’s consciousness.

\section{[INSERT FIGURE 3 HERE}

caption: (Okubo [1946] 2014, 10)]

The need to rid oneself of this discourse is implied by the blank space on the opposite page, which functions as a variation of the gutter. Here it becomes a space of contemplation in which Okubo and the reader can reflect, clear their minds and prepare for what lies ahead. As the commentary sardonically advises, in the words of a Japanese American "brother": “Better get ready for induction, kids. It’s your turn now!” ([1946] 2014, 11). On the next page is another white space that illustrates the "unforeseen difficulties" caused by "growing suspicion and general public antagonism” ([1946] 2014, 13). As forced evacuation is 
introduced, the white space signals an unknown future and the loss of Japanese American autonomy.

Time is important to the process of persecution. One of the headline slogans reads “CURFEW MUST BE OBEYED BY ALIENS AND CITIZENS OF JAP ANCESTRY” ([1946] 2014, 10), and it is evident that the authorities controlled time to exercise power and mark difference. As Okubo explains: “All American citizens and aliens of Japanese ancestry and other enemy aliens had to be home between the hours of 8 P.M. and 6 A.M. I had to have a special permit to travel to Oakland where I was employed because it was outside a five-mile radius of my home. Violation of any of the regulations meant fines and imprisonment” ([1946] 2014, 14). The accompanying image, in which a disgruntled Okubo hurries home and looks back at an officer who is presumably there to check that people are adhering to the curfew, is therefore powerfully chronotopic (Figure 4).

[INSERT FIGURE 4 HERE

caption: (Okubo [1946] 2014, 14)]

In showing how the curfew affects both Okubo's interaction with familiar spaces and with people, it demonstrates how "[t]ime, as it were, thickens, takes on flesh, becomes artistically visible; likewise, space becomes charged and responsive to the movements of time, 
plot, and history” (Bakhtin 1978, 493). Linking time, space and external authority, it also predicts one of the camp images most discussed by critics — the one in which Okubo is shown sticking her tongue out at the "house captain" whose job it is to enforce the Tanforan curfew ([1946] 2014, 59). Heather Fryer (2008) correctly sees this image as pivotal: each subsequent picture, she argues, becomes "a blow to the system that sought not only to control her but to control how people would understand her experience as an internee” (88). Okubo is holding a paint brush, which suggests that though her time may not have been her own inside the camps, her drawings were, and they pointed to a future in which Japanese Americans, through the telling of their stories, could reclaim the time of their internment.

In tracing the links between pre-camp images and images depicting life in Tanforan and then Topaz, Citizen 13660 "demands a reading capable of searching, [...] to the aspects or fragments of panels susceptible to being networked with certain aspects or fragments of other panels” (Groensteen 2007, 146). This is a feature of all comics, because in the multi-framed form "every panel exists, potentially if not actually, in relation with each of the others" (146). This formal characteristic and the hermeneutic possibilities it opens up complicate conceptions of national identity just as they do a linear narrative structure. As I have argued before, the factitious sense of a "before" and "after" implied in the concept of "descent" or "ancestry" can be utilised in anti-Japanese American discourse and the championing of a supposedly undiluted, unhyphenated “American” identity. 
This is why one of the scare headlines encircling Okubo's body is of particular importance. Although it is partially obscured by another slogan, the words "SEND THEM BACK TO TOJO” are clearly visible. This is a reference to Hideki Tojo, Prime Minister of Japan from October 171941 to July 22 1944, who ordered the attack on Pearl Harbor. The chronotopic weight of the preposition "back", simultaneously carries spatial and temporal references to a supposedly proper place - Japan - to where the Japanese Americans will be sent, and a proper time, the "before" of the ancestral homeland, whether or not individual Japanese Americans have ever set foot there. The text utilises the irruptive historical force of the attack on Pearl Harbor ${ }^{3}$ to alter the conception of their belonging to the nation, to disrupt their ethnic and national identity through changing the perception of their spatiotemporal affiliations.

Japanese Americans thus come to be viewed as anomalous, as positioned outside (and thus a threat to) the "temporal coincidence" and the necessary "simultaneity" that, as Benedict Anderson argues, allows for an imagining of national community ([1983] 2006, 24, 25). Anderson’s famous notion of the “meanwhile”, derived from Walter Benjamin’s (1968) description of "homogenous, empty time" measured by clock and calendar (161), provides a kind of melting-pot in which distinctions can be neutralised. As Homi Bhabha says:

The steady onward clocking of calendrical time, in Anderson's words, gives the 
imagined world of the nation a sociological solidity; it links together diverse acts and actors on the national stage who are entirely unaware of each other ([1994] 2004, 226; original emphasis)

So the national population, "however divided and split, can still assume, in the function of the social imaginary, a form of democratic 'anonymity’” ([227). Through racist epithets, visual caricatures and the sense that somehow they belong elsewhere and in another time away from the benign present of "Americanness" - such "anonymity” is denied to Japanese Americans. Among the scare headlines, for example, is a tiny sketch accompanying the words "A JAP LOOKS LIKE THIS” ([1946] 2014, 10). Okubo's graphic representation shows the internment camps as places of spatial control and exclusion, designed to exacerbate perceived difference and make time move less progressively than in the rest of the nation.

For Homi Bhabha, critiquing Anderson's ideas, "the narrative of the imagined community is constructed from two incommensurable temporalities of meaning that threaten its coherence" ([1994] 2004, 227) - the "meanwhile" of national identification and the special kind of community identification rooted in language. Because nobody can give a date of origin for a language, it seems to emerge suddenly and "imperceptibly out of a horizonless past” (Anderson [1983] 2006, 144). It is this "sudden primordiality of meaning” (Bhabha [1994] 2004, 228) that destabilises the meanwhile, and it is part of a wider issue with 
language — the arbitrariness of its signs, which are "neither synchronous nor serial" (227). Bhabha agrees with Lévi-Strauss that things cannot signify gradually, they just signify: language means suddenly and thus cannot readily be historicized and assimilated into the realist, novelistic narrative of nationhood Anderson describes. Bhabha's critique of Anderson argues that rather than simultaneity, there is "a temporal break" from the reproduction of similar moments characteristic of homogenous empty time, and likewise "a spatial disjunction” (Bhabha [1994] 2004, 228).

Bhabha sees in this disruption the potential for alternative, liminal postcolonial voices, national subjects “'in-between', or in excess of, the sum of the 'parts’ of difference” ([1994] 2004, 2). He states: "From the place of the 'meanwhile' [. . .] there emerges a more instantaneous and subaltern voice of the people, minority discourses that speak betwixt times and places” (227). The complex interplay of sequential, serial and translinear readings in Citizen 13660 allows the subaltern voice to speak in ways that challenge not only the stories told about Japanese Americans during the war, but also fixed notions of national identity.

Crucial to this, as I have suggested already, is "braiding", the locating of echoes and connections beyond the linear sequencing of panels. The sometimes contradictory relationship between words and images of the graphic novel provides a powerful analogy to the productive disruption of which Bhabha writes: the ironies of Okubo's words frequently break up the linear narrative or fold it in upon itself, thus forcing a re-evaluation of what has gone before. Okubo 
(in conjunction with the reader) is therefore able to turn the discursive and representational strategies of her persecutors back upon them, to disrupt homogenous, empty time and thus to show that identities are invariably formed between times and places.

When one compares transitions between panels in different sections of Citizen 13660, it is evident that the representation of time changes dramatically to mirror the change in the lived experience of time from pre-camp life to internment. As Megan Kelso (2004) argues, "the part that works most like comics” (para. 6) covers the day Okubo and her brother are evacuated to Tanforan. It begins with the imposition of their new identity as they pin the "personal tags" bearing the number “13660” on themselves and their luggage (Okubo [1946] 2014, 22), and ends with Okubo's doomed attempt to get some sleep on her first night in captivity. The dominant progression in this section is what McCloud labels "action-to-action" $(1993,70)$. The narrative moves in linear fashion through the day, chronicling each significant stage in the evacuation process: turning to take "one last look at our happy home” (Okubo [1946] 2014, 23); the arrival at Tanforan (27); the medical examination (31); the first suppertime (39); and finally the attempts to sleep on mattresses filled with straw (47). The reader is encouraged to experience events sympathetically as they unfold and to feel the strangeness and pain of the transition from freedom to incarceration. The affective power of the sequence is enhanced rather than offset by the meticulous care with which Okubo depicts the order and the timing of these events, which betrays her desire to show that she is still aware of, and to some extent in 
control of, the passing of time. Thus she notes that her group was called to leave the Civic Control Station at 11.30 a.m.; that they arrived at Tanforan at approximately 12.30 p.m.; that they waited in the bus for fifteen minutes (28); that suppertime was at four o'clock (her exactitude is only reprised much later in the book when she and other internees are transferred to Topaz in Utah on a train that departs “at exactly 7.45 P.M.” and arrives in Salt Lake City at 4 a.m. [118]).

For the most part, the reader can easily achieve “closure” between panels — McCloud's term for the "phenomenon of observing the parts but perceiving the whole" in comics narratives (1993, 63). Evacuation has a brutal procedural logic and the events themselves by this stage have an aura of inevitability. Where Okubo does leave gaps is in the portrayal of her emotional responses; she creates a characteristic disjunction between the laconic textual commentary and the more revealing image. For example, accompanying the simple sentence "we took one last look at our happy home” (23) there is a picture of Okubo and her brother standing beside the open door of their car and gazing back at their house (Figure 5). In a nod to comics convention, two tears are drawn on Okubo's left cheek. These tears, by their very existence, reveal the depth of feeling merely suggested by the word "happy". But because they exist in time as well as in space, and because the image can only imply the time they take to move down Okubo's face, they reinforce the significance of this moment in time, as one to be slowed down and lingered over. This simple addition invests the image with tremendous 
emotional and memorial resonance, therefore, but also predicts the retardation of time that will be evident in the pages pertaining to the internment. Like other subtle touches in Citizen 13660 it belies the claims of postwar critics that Okubo's memoir is a model of objectivity, even detachment (Fryer 2008, 92).

\section{[INSERT FIGURE 5 HERE}

caption: (Okubo [1946] 2014, 23)]

Once Okubo settles into camp life, the implied temporal scope of the images changes, and typical transitions between panels are more likely to be "subject-to-subject" or “aspect-to-aspect,” (McCloud 1993, 71-72) covering greater distances spatially and temporally (though almost always within the confines of the camp) and demanding a higher degree of reader involvement. Beneath a picture of Okubo, her brother and another internee working with wooden planks to improve their living quarters, the commentary begins: "The first month was the hardest because adjustments had to be made to the new mode of life" (Okubo [1946] 2014, 50). Subsequent panels depict further carpentry work within the barracks; the clothes of the internees; Okubo's grandstand view of the new evacuees' arrival at Tanforan, "at the rate of three hundred a day" (53); and the administration of typhoid and smallpox vaccinations (54). In all of these panels, “time appears to stagnate” (Earle 2013, 5), 
to become what Bakhtin (1978) calls "thick, sticky time, which oozes in space" (523) and describes not a progressive trajectory but a set of repeated actions over time, most externally imposed upon the internees.

However, Okubo's habit of watching each set of new arrivals "go through the induction steps I had gone through a couple of weeks earlier" inspires her decision to "keep a record of camp life in sketches and drawings” (Okubo [1946] 2014, 53), and thus constitutes the moment she assumes control of representing the repetitions and privations imposed upon her companions. From this panel onwards, Okubo recasts herself as observer and recorder, but this status reverberates back through what has gone before, too, further upsetting a straightforward linear chronology. The reader is made aware that Okubo has always been observing, and that previous images in the text, which seem to depict her as protagonist, are layered and complex, revealing the reflexivity of the autobiographical act. As Stella Oh (2008) explains, by including herself as spectator in the camp panels Okubo "addresses the ways in which our visual productions shape our social perceptions along with our individual opinions” (150); Okubo also contests authority and its use of surveillance, for example by spying on the camp guard who is spying on Japanese American men playing cards (Okubo [1946] 2014, 60) (Figure 6). Our understanding of the memoir's representational mode significantly changes with the shift here from the predominantly realist personal memoir of the pre-camp pages (apart from the "scare headlines" image), to a meta-reflexive realism whose subject is both 
the facts of Japanese American internment and the politics of their representation. As Okubo records the repeated, wearisome tasks of camp life, her presence within the images, mediating the reader's gaze, renders these tasks and events not as objective, neutral occurrences but as performances.

\section{[INSERT FIGURE 6 HERE}

caption: OKUBO [1946] 2014, 60]

. As Bhabha argues: "terms of cultural engagement, whether antagonistic or affiliative, are produced performatively” (Bhabha [1994] 2004, 3). Thus difference derives not from “pre-given ethnic or cultural traits” but from “a complex, on-going negotiation” between social performances of belonging (Bhabha [1994] 2004, 3). “Nation” relies on "tradition”, but Bhabha sees tradition constantly conditioned and challenged by those in a contested or contradictory relationship to it - those in a minority, those marginalised by hegemonic discourses. Japanese Americans in Citizen 13660 are, at a time of historical upheaval, cast out of one version of Americanness and consigned to a margin in which their spatiotemporal loyalties are questioned: the camps, as depicted by Okubo, concretise their marginality and condemn them to repeated actions supposedly outside the "meanwhile" of the American nation, even as the pioneer metaphors applied to their experience aim at a disavowal of their 
exclusion. Citizen 13660 works effectively as an ironic "theory of citizenship" precisely because - in showing how the Japanese Americans are forced repeatedly to perform their outsider identities - it shows how all national identities rely on such performances for their supposed legitimacy. The dominant group may not see its identity as performative or constructed, but as natural or essential: pledging allegiance to the flag is a familiar example of a symbolic, performative act repeated often enough to become reified and naturalised. But in repeatedly forcing a racial other to perform in this way, the dominant group undermines its own sense of normativity or naturalness.

Two incidents Okubo describes in the Topaz camp make this especially apparent. Among other educational activities at Topaz, the Issei internees are treated to “Americanization classes” (Okubo [1946] 2014, 167). As a Nisei, Okubo’s presence is presumably not compulsory, and yet in the picture of the class she is there, observing from the back row as the teacher, standing next to a large American flag, declaims on what it means to be American. The flag is truncated by the top of the panel, humorously suggesting both the "incompleteness" of the Issei's education and the limits of the symbolic identification with the flag. Again, attempts at indoctrination undermine themselves by revealing the instability of identities: the class shows that all national affiliations are constructed, learned and performed rather than innate, while the teacher, positioned as if on a stage, theatrically holding aloft his pointer, suggests performance as much as pedagogy. This 
suggestion is reinforced in subsequent pages, which describe entertainments and events including "art and hobby shows" (169), "Sumo performances” (171) and the talent shows and plays presented "on makeshift stages in the mess halls" (173). The context and positioning of the Americanization class serve to compound its performative status.

The same can be said of the recruitment drive that follows President Roosevelt's announcement, on January 29, 1943, that Japanese American volunteers were to be accepted into the army. A member of the "recruiting team" stands upon a stage in the Topaz centre, clutching a handkerchief and emotively proclaiming to an audience of internees his "loyalty and willingness to fight” (Okubo [1946] 2014, 175). To exaggerate the air of theatricality, many of the audience are shedding tears, visibly moved by this performance of patriotism (Figure 7). Okubo, in contrast, does not reprise the tears she shed on departing her California home: she holds her nose in disgust and stares not at the performer, but at the reader; the alienating effect invites the reader to consider dispassionately the politics at work and not to be swayed by the emotive rhetoric. Again, there is tension between image and text. While the former emphasises and critiques the affective aspects of national affiliations, the latter emphasises the bureaucratic and juridical, as it describes the complicated form men of military age are required to complete. Most ideologically significant is Question 28, which reads: "Will you swear unqualified allegiance to the United States of America and forswear any form of allegiance to the Japanese Emperor or any other foreign power or organization?» 
(175). Neglecting to define how “allegiance” might be measured, the question requires only a performative utterance. And as Okubo implies, it betrays the contradictory approach to ensuring a uniform national identity through division. On the one hand, it invites Issei to become effectively stateless; on the other, it seems to test Nisei loyalty "at the moment when the army was asking them to volunteer” (176). Reference to the Japanese Emperor recalls the earlier demand to "send them back to Tojo," but this time insists on total renunciation — of the prohibited space of the mother country, of the prohibited time of Japanese ancestry. The result of the initiative is, inevitably, segregation: in late 1943 "thirteen hundred Topazians (about one tenth of the total)” are moved to Tule Lake on suspicion of continuing “disloyalty” (199). Some are forced to go simply so they can stay with their families.

\section{[INSERT FIGURE 7 HERE}

caption: (Okubo [1946] 2014, 175)]

These examples from Citizen 13660 suggest that the camps functioned as laboratories for experiments on a marginalised ethnic group in order to reinforce a notion of homogenous American identity. Thus Okubo's representation of the camp experience, with its ironic juxtapositions of text and image and inclusion of the author herself as witness, reveals the instability of national identity and the contradictory discursive strategies employed in its 
service. The "enforced invisibility of Japanese Americans in the public space of the nation" stands in contrast to their visibility as "targets of surveillance" (Oh 2008, 146). And yet, through the representation of that invisibility in Citizen 13660, and in the first-person accounts collected in Only What We Could Carry (Inada 2000) and Monica Sone’s (1979) Nisei Daughter, we are reminded that nationhood derives from the supplementary play of supposed opposites: visible and invisible, central and marginal, loyal and disloyal, before and after. Bhabha says that new approaches to nationhood emerge from "the enunciative boundaries of a range of other dissonant, even dissident histories and voices” ([1994] 2004, 6): Okubo's text constitutes such an enunciative boundary, and its formal properties undermine a processual narrative analogous to "homogenous empty time," exposing the cracks in the supposed solidity of the "meanwhile."

Additionally, the memoir's interplay of image and text serves to interrogate and undermine the discursive strategies of authority. The two most powerful examples exploit comics visual conventions to collapse the opposition of natural and ideological. In Tanforan the weather is described as "fair" but the people are shown hiding their faces and holding onto their hats to protect themselves from the incessant wind and dust (Okubo [1946] 2014, 56). As Stella Oh notes, the implied pun subtly conflates and throws into question different meanings of the word "fair" - meteorological and ethical (2008, 152). A similar strategy is employed later in the text (Figure 8): even though the spring weather in Topaz is described as 
"mild," there is a fierce wind which blows "from all points of the compass most of the time" (Okubo [1946] 2014, 183). It is drawn comics-style, with exaggerated motion lines. This can be interpreted both as a "natural" force that is beholden to no political institution and, as the compass reference indicates, a universal part of human experience. In the context of the camps it represents an unseen power visible only through its material effects. Thus it is analogous to abstract notions of nationhood and belonging which, through their insistent repetition and representation, become reified, believable as aspects of a "natural" authority.

The use of deliberately unrealistic comics conventions lays bare this process.

\section{[INSERT FIGURE 8 HERE}

caption: Okubo [1946] 2014, 183)]

In a book dedicated to irony, contestation and ambiguity, the ending, ostensibly so optimistic, should be approached cautiously. Having finished her "documentary sketches of camp life” (Okubo [1946] 2014, 206), Okubo prepares to leave Topaz, declaring: “I was now free" (208; emphasis in original). The italics connote equivocation and challenge the reader to consider what that freedom might mean. The last image shows Okubo looking back with sadness and sympathy at the Topaz internees, saying "there was only the desert now. My thoughts shifted from the past to the future” (209). This shift feels too abrupt: Citizen 13660 
has demonstrated how complex relationships between past, present and future are and how identity cannot be regarded in linear terms. The image of the desert suggests at best an unknown future, at worst a barren one. Okubo seems to know that her freedom is provisional and uncertain. And as Heather Fryer shows, for all Okubo's intelligence in re-claiming the stories and the visual representations of the Japanese Americans during World War Two, she had little control over the reception of her work. Citizen 13660 was taken as proof that Okubo was, on balance, “more American than Japanese,” the supposedly American “objectivity”, outweighing her work’s more "Japanese” artistry (Fryer 2008, 93). Thus many reviews appeared to reinforce the essentialist notions the book was working against. Okubo's future, though she could not have known it when she left Topaz, would involve the retelling of the story through testimony and teaching, as part of a continual negotiation of Japanese American identity.

\section{Acknowledgements}

All images are reproduced with the permission of the Estate of Miné Okubo. The author wishes to thank Seiko Buckingham for permission to use them.

\section{Notes on contributor}

James Peacock is Senior Lecturer in English and American Literatures at Keele University in the UK. He is the author of Jonathan Lethem (Manchester University Press) and Brooklyn Fictions: the Contemporary Urban Community in a Global Age (Bloomsbury).

\section{References}


Anderson, Benedict. [1983] 2006. Imagined Communities: Reflections on the Origin and Spread of Nationalism. London and New York: Verso Books.

Bakhtin, Mikhail. 1978. "The Forms of Time and the Chronotopos in the Novel: From the Greek Novel to Modern Fiction.” Journal of Descriptive Poetics and Theory of Literature 3: 493-528.

Benjamin, Walter. [1955] 1968. “Theses on the Philosophy of History.” In Illuminations, edited by Hannah Arendt, 253-264. New York: Schocken Books.

Bhabha, Homi. [1994] 2004. The Location of Culture. London and New York: Routledge.

Chin, Vivian Fumiko. 2004. "Gestures of Noncompliance: Resisting, Inventing, and Enduring in Citizen 13660.” Amerasia Journal 30 (2): 23-42.

Creef, Elene Tajima. 2004. Imaging Japanese America: The Visual Construction of Citizenship, Nation, and the Body. New York: New York University Press.

Earle, Harriet. 2013. “Comics and the Chronotope: Time-Space Relationships in Traumatic Sequential Art." HARTS and Minds: the Journal of Humanities and Arts 1 (2). <http://media.wix.com/ugd/3089fd_e978e044934f3aa4390bb478863d24d6.pdf>

Fryer, Heather. 2008. “Miné Okubo’s War: Citizen 13660's Attack on Government Propaganda.” In Greg Robinson and Elena Tajima Creef, eds., Miné Okubo, 82-98. Seattle, WA: University of Washington Press.

Groensteen, Thierry. 2007. The System of Comics. Translated by Bart Beaty and Nick Nguyen. Jackson, MI: University of Mississippi Press.

Inada, Lawson Fusao, ed. 2000. Only What We Could Carry: The Japanese American Internment Experience. Berkeley, CA: Heyday.

Kelso, Megan. 2004. “Miné Okubo’s Citizen 13660.” Indy Magazine. $<$ http://www.indyworld.com/indy/summer_2004/kelso_okubo/index.html>

McCloud, Scott. 1993. Understanding Comics: The Invisible Art. New York: Harper Perennial. 
Nguyen, Viet Thanh and Tina Chen. 2000. "Postcolonial Asian America: Editors' Introduction." Jouvert: a Journal of Postcolonial Studies 4 (3). $<$ http://english.chass.ncsu.edu/jouvert/v4i3/ed43.htm>.

Okubo, Miné. [1946] 2014. Citizen 13660. Seattle, WA: University of Washington Press.

Phillips, Kimberley L. 2005. "Keeping a Record of Life: Women and Art during World War II.” Magazine of History 19 (2): 20-24.

Robinson, Greg. 2004. "What I Did in Camp: Interpreting Japanese American Internment Narratives of Isamu Noguchi, Miné Okubo, Jeanne Wakatsuki Houston, and John Tateishi.” Amerasia 30 (2): 49-58.

Robinson, Greg and Elena Takima Creef. 2008. Miné Okubo: Following Her Own Road. Seattle, WA: University of Washington Press.

“Roosevelt Bars the Hyphenated.” 1915. New York Times, October 13.

Smith, Sidonie. 2011. "Human Rights and Comics: Autobiographical Avatars, Crisis Witnessing, and Transnational Rescue Networks.” In Graphic Subjects: Critical Essays on Autobiography and Graphic Novels, edited by Michael A. Chaney, 61-72. Madison, WI: University of Wisconsin Press.

Sone, Monica. 1979. Nisei Daughter. Seattle, WA: University of Washington Press.

Zhou, Xiaojing. 2007. “Spatial Construction of the 'Enemy Race’: Miné Okubo’s Visual Strategies in Citizen 13660.” MELUS 32 (3): 51-73.

\section{Notes}

\footnotetext{
1 And often enshrined in law: the Naturalization Act of 1870, for example, extended citizenship to African Americans but not to Asian Americans.

${ }^{2}$ Later in the story, as Okubo and her brother are being led to the barracks at Tanforan Race Track, she turns to look directly at the reader again. Heather Fryer (2006) reads this as a challenge to the reader to disbelieve and denounce the pioneer story with which the authorities were trying to frame the internment process (86). It is another example of braiding.

3 This is itself a chronotope: "Pearl Harbor" has come to refer to both a place and an event.
} 